\title{
Acute Appendicitis Following Colonoscopy
}

\author{
Geoffrey Yuet Mun Wong, MBBS, Conrad Viktor Stranz, MBBS \\ Department of General Surgery, Modbury Hospital, Modbury, South Australia (all authors).
}

\begin{abstract}
Background: Acute appendicitis after colonoscopy is a rare sequela and may be incidental or a true complication of colonoscopy. This review explores the cause and effect relationships between colonoscopy and the development of acute appendicitis.

Methods: We conducted a systematic review of the literature to identify articles up to July 2011. The following time intervals were collated from documented cases to evaluate the natural history of postcolonoscopy appendicitis: time from colonoscopy to symptom onset, time from symptom onset to presentation (preadmission delay), and time from symptom onset to surgery. Postadmission delay was then estimated.

Discussion: Paucity of published cases on postcolonoscopy appendicitis may be the result of acute appendicitis being incidental after colonoscopy or because of under-recognition of this complication. The close association between colonoscopy and the onset of symptoms of acute appendicitis suggests a relationship between the procedure and pathology. However, at present, the data available are inadequate to give firm details on the natural history of acute appendicitis after colonoscopy. Shared symptomatology and examination findings between postcolonoscopy appendicitis and common colonoscopic complications such as colonic perforation and postpolypectomy syndrome result in delayed diagnosis. Our findings suggest that delayed surgical intervention is associated with increased morbidity and mortality and is clinician dependent in a majority of cases.
\end{abstract}

Conclusion: Regardless of whether postcolonoscopy appendicitis represents an incidental finding or true complication of colonoscopy, consideration of acute appendicitis as a differential diagnosis of the acute abdomen after colonoscopy is important.

Key Words: Colonoscopy, Postcolonoscopy, Acute appendicitis.

Citation Wong GYM, Stranz CV.Acute appendicitis following colonoscopy. CRSLS e2014.00121. DOI: 10.4293/CRSLS.2014.00121.

Copyright (C) 2014 SLS This is an open-access article distributed under the terms of the Creative Commons Attribution-Noncommercial-ShareAlike 3.0 Unported license, which permits unrestricted noncommercial use, distribution, and reproduction in any medium, provided the original author and source are credited.

The authors acknowledge Dr. George Barreto, Dr. Phil Worley, Dr. Frank Voyvodic, Daniel Crawford, and Chelsea Jaensch for their surgical and technical assistance.

Address correspondence to: Geoffrey Yuet Mun Wong, MBBS, Department of General Surgery, Modbury Hospital, Smart Road, Modbury, South Australia 5092

Telephone: +61413104617, Fax: +61881612174, E-mail: geoffwong05@gmail.com

\section{INTRODUCTION}

Colonoscopy is generally a safe procedure that may enable visual examination from anus to cecum. Biopsy of lesions and therapeutic interventions such as polypectomy are commonly performed during colonoscopy and are associated with a higher incidence of postprocedural complications. ${ }^{1}$ Bleeding episodes, colonic perforation, and abdominal pain are known complications of colonoscopy, and the incidences of these complications have been reported to be $0.21 \%, 0.1 \%$, and $0.08 \%$, respectively, in an Australian teaching hospital environment. ${ }^{1}$ The risk of perforation of the colon is, however, higher with polypectomy, estimated at $0.3 \%$ to $1.0 \%{ }^{1}$ Postpolypectomy syndrome is a recognized complication that occurs after polypectomy with electrocoagulation and is characterized by abdominal pain, fever, and leukocytosis without evidence of perforation. ${ }^{2}$

Acute appendicitis after colonoscopy is a rare sequela, reflected in the paucity of literature available on this condition. We identified 30 cases in 24 articles since the first reported case by Houghton and Aston in 1988. The few published cases of postcolonoscopy appendicitis may be the result of acute appendicitis being incidental after colonoscopy or because of under-recognition of this complication. ${ }^{3}$ The latter may be the result of successful con- 
servative treatment, such as intravenous antibiotics instituted for a clinical diagnosis of limited perforation in the absence of adequate diagnostic imaging such as computed tomography (CT).

We propose that progression of symptoms and clinical signs of acute appendicitis after colonoscopy is rapid and thus accurate clinical recognition is imperative. This review explores the cause and effect relationships between colonoscopy and the development of acute appendicitis after this procedure.

\section{Case}

A 47-year-old man underwent colonoscopy for investigation of rectal bleeding. Two rectal polyps were removed during the procedure. He was discharged shortly after the procedure and was able to tolerate oral intake later that evening. Thirteen hours after colonoscopy, he awoke with sharp, constant, generalized abdominal pain associated with nausea. He had not had a bowel movement or passed flatus after the procedure. He presented to the emergency department 4 hours after the onset of symptoms, approximately 17 hours after the procedure. He was noted to be afebrile but had lower abdominal tenderness, especially of the right lower quadrant.

Routine hematologic studies revealed neutrophilia but a normal C-reactive protein level. There was no free subdiaphragmatic air on his erect chest radiograph. A plain abdominal radiograph showed fecal material in the right colon but was otherwise unremarkable. The clinical impression was a limited perforation or postpolypectomy syndrome secondary to colonoscopy. Because of this suspicion, a CT scan of the abdomen and pelvis was arranged, and showed no extraluminal gas or free fluid. Incidentally, a retrocecal appendix containing an appendicolith and distended to $13 \mathrm{~mm}$ was identified (Figures 1 and 2). There was, however, minimal associated mesenteric fat stranding. Serial clinical examinations revealed rapid development of a low-grade fever and well-localized right lower quadrant peritonism.

In light of this clinical progression, he underwent exploratory laparoscopic surgery 22 hours after the onset of symptoms, 18 hours after his presentation to the emergency department. A 5-hour postadmission delay to surgery was unavoidable because of an unavailability of emergency operating rooms. Visualization of the abdominal cavity revealed postileal suppurative appendicitis with free pus in the pelvis. The procedure was converted to a midline laparotomy because the appendix could not be mobilized safely. Postoperatively, he was treated with

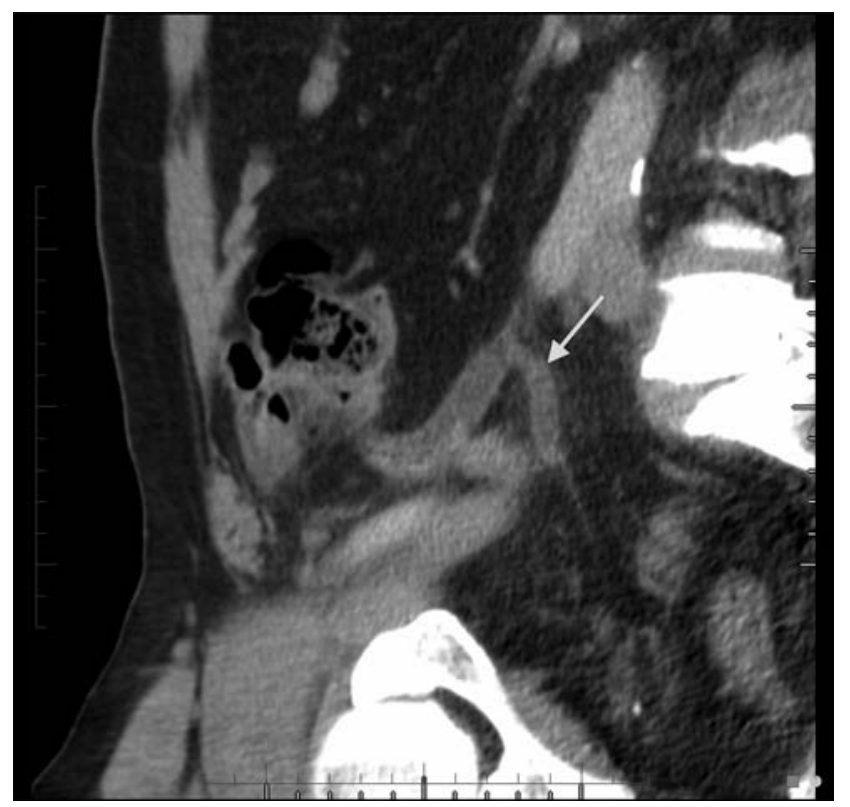

Figure 1. Obliquely reformatted CT scan image of the abdomen to highlight the distended appendix, with a fecalith seen in proximal lumen.

intravenous antibiotics (amoxicillin, metronidazole, and gentamicin) for 24 hours, followed by a further 5 days of oral antibiotics (amoxicillin/clavulanate). He made an unremarkable recovery and was discharged on the third postoperative day.

\section{METHODS}

A systematic review of the literature was performed to identify articles up to July 2011. Searches were conducted using the PubMed, Medline, and EMBASE databases. Relevant abstracts and full text articles about acute appendicitis after colonoscopy were selected from articles generated with the following search terms: appendicitis/ etiology, colonoscopy/adverse effects, postcolonoscopy, and polypectomy. A manual search was also conducted through references of articles. Full-text articles were sourced through interlibrary requests if they were unavailable from electronic health databases. No language restrictions were applied. All foreign language articles were translated into English by fluent speakers in both the language of the original text as well as English. All translators had an understanding of medical terminology. There were no restrictions on the time to onset of symptoms from colonoscopy to be considered a complication of the procedure. 


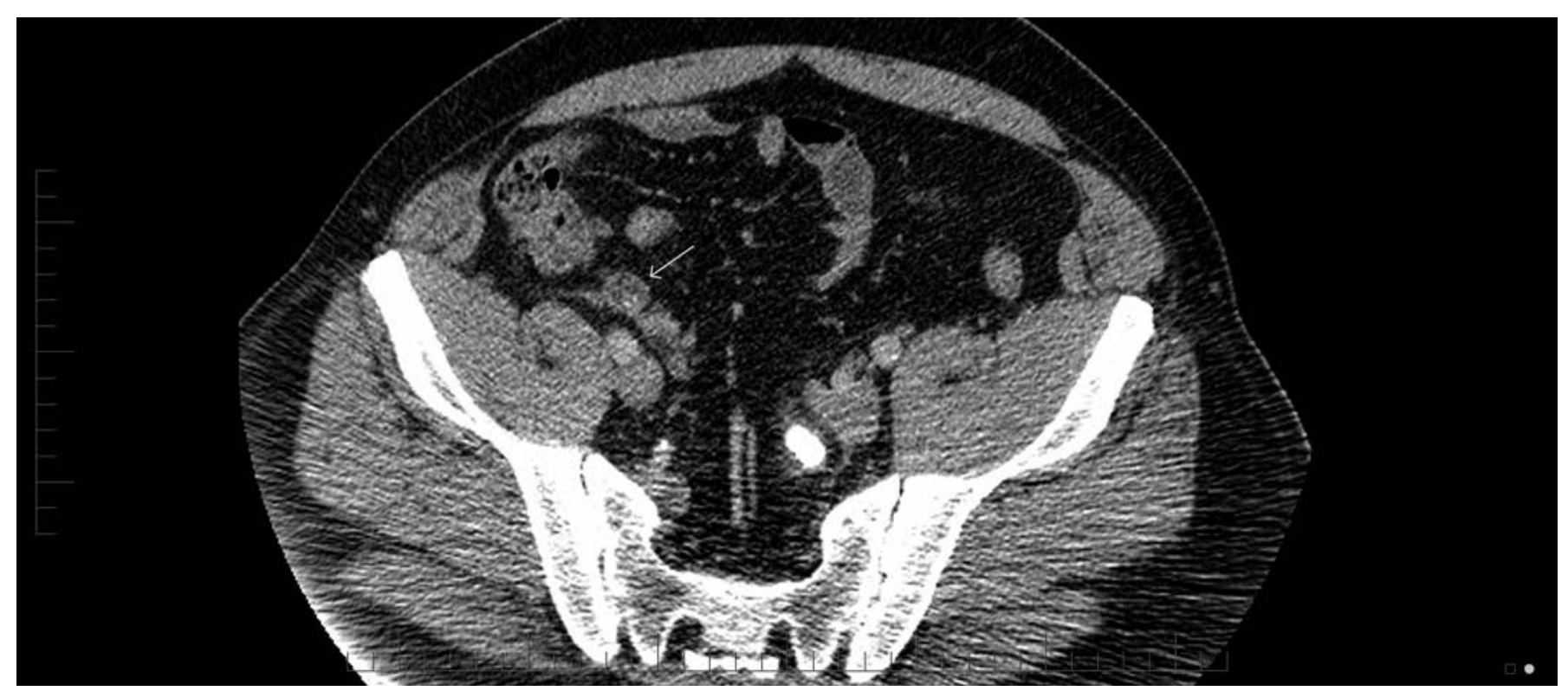

Figure 2. Axial abdominal CT scan image showing a distended appendix and an intraluminal fecalith.

The following time intervals were collated from documented cases to evaluate the natural history of postcolonoscopy appendicitis:

A. Time from colonoscopy to symptom onset.

B. Time from symptom onset to presentation (preadmission delay).

C. Time from symptom onset to surgery.

The time from presentation to surgery (postadmission delay) was estimated by subtracting B from C. The total delay from symptom onset was obtained by adding preadmission and postadmission delay. Qualitative time descriptions were converted to quantitative time intervals measured in hours. Time intervals to symptom onset, presentation to hospital, and surgery occurring on the day of colonoscopy were estimated to be 12 hours from colonoscopy, whereas events after the day of the procedure were approximated to the nearest 24-hour time interval.

\section{RESULTS}

Table 1 shows data collated from the review of 31 cases: 24 articles comprising 30 case reports in addition to the authors' case. The patient demographic data consisted of 22 male patients (71\%) and 9 female patients (29\%). The combined mean age was 55.5 years (range: $24-84$ ). Eight patients underwent a diagnostic colonoscopy exclusively, and 23 patients had an intervention performed, with polypectomy being the most common intervention.

The median time to symptom onset from colonoscopy was 12 hours, ranging from immediately after to 5 days after colonoscopy (Table 2). Twenty-three (74\%) patients had symptoms within 24 hours of colonoscopy, with 19 (61\%) of the total number of patients experiencing symptom onset within 12 hours of their procedure. The remaining 8 patients (26\%) experienced symptom onset between 25 hours and 5 days after colonoscopy.

The patient diagnoses were divided into 2 major groups: $15(48.4 \%)$ with an acutely inflamed appendix and 16 (52\%) with complicated appendicitis (Figure 3). Complicated appendicitis cases included diagnoses of phlegmonous appendicitis, perforated appendicitis, and pelvic appendiceal abscess, which numbered 4 (13\%) cases, 11 (36\%) cases, and 1 case (3\%), respectively.

Time intervals of postcolonoscopy appendicitis were semiquantitatively compared with the natural history of conventional appendicitis to determine whether time to surgery was a result of patient or clinician delay. ${ }^{27,28}$ Only 11 of 31 cases were analyzed because insufficient documentation precluded comparison of the remaining cases. Ten of 11 (91\%) cases of delay to surgery were attributable to the length of time taken for in-hospital evaluation, whereas the remaining case demonstrated both patient and clinician delay. Six of 11 (55\%) perforations, 1 case of 


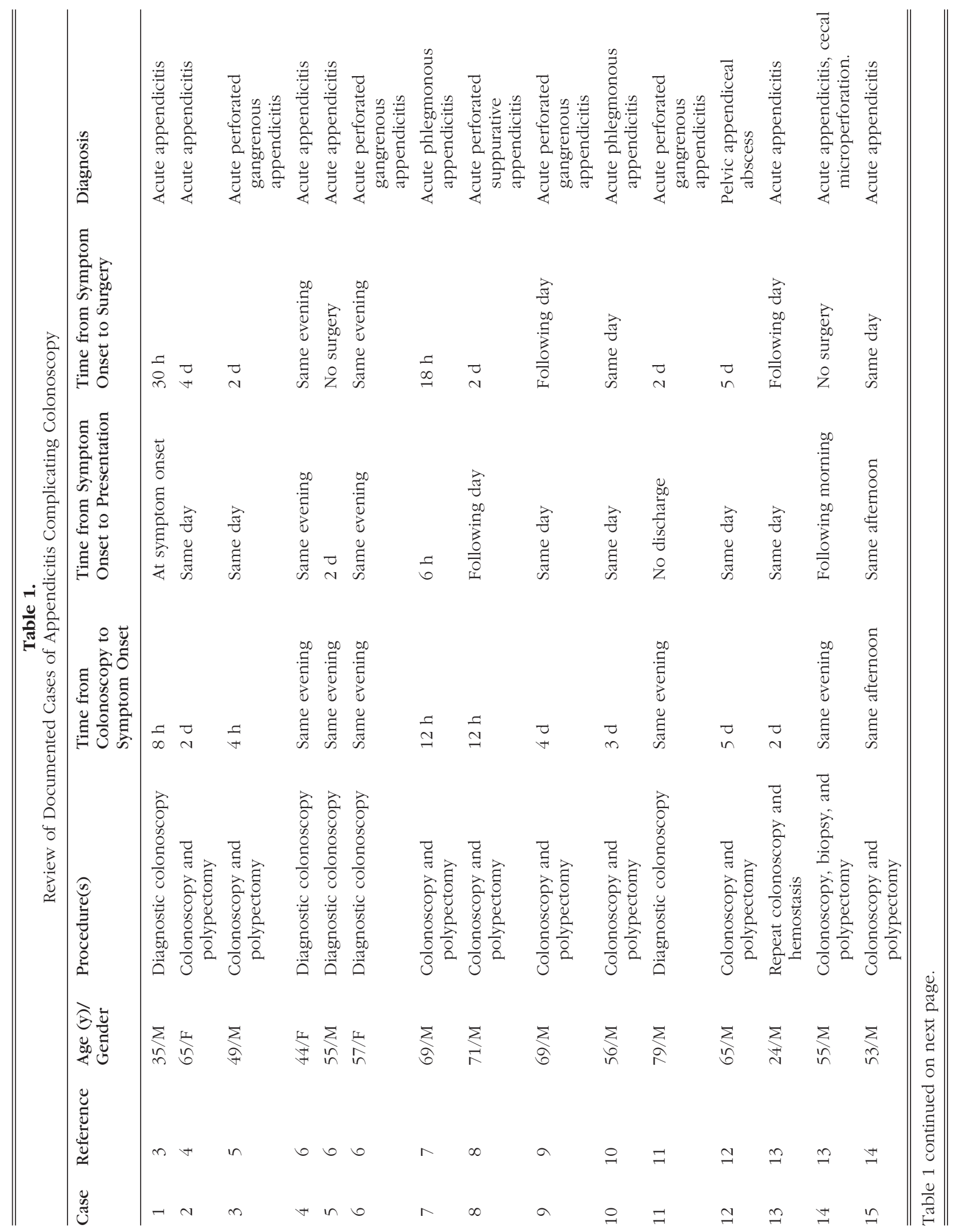




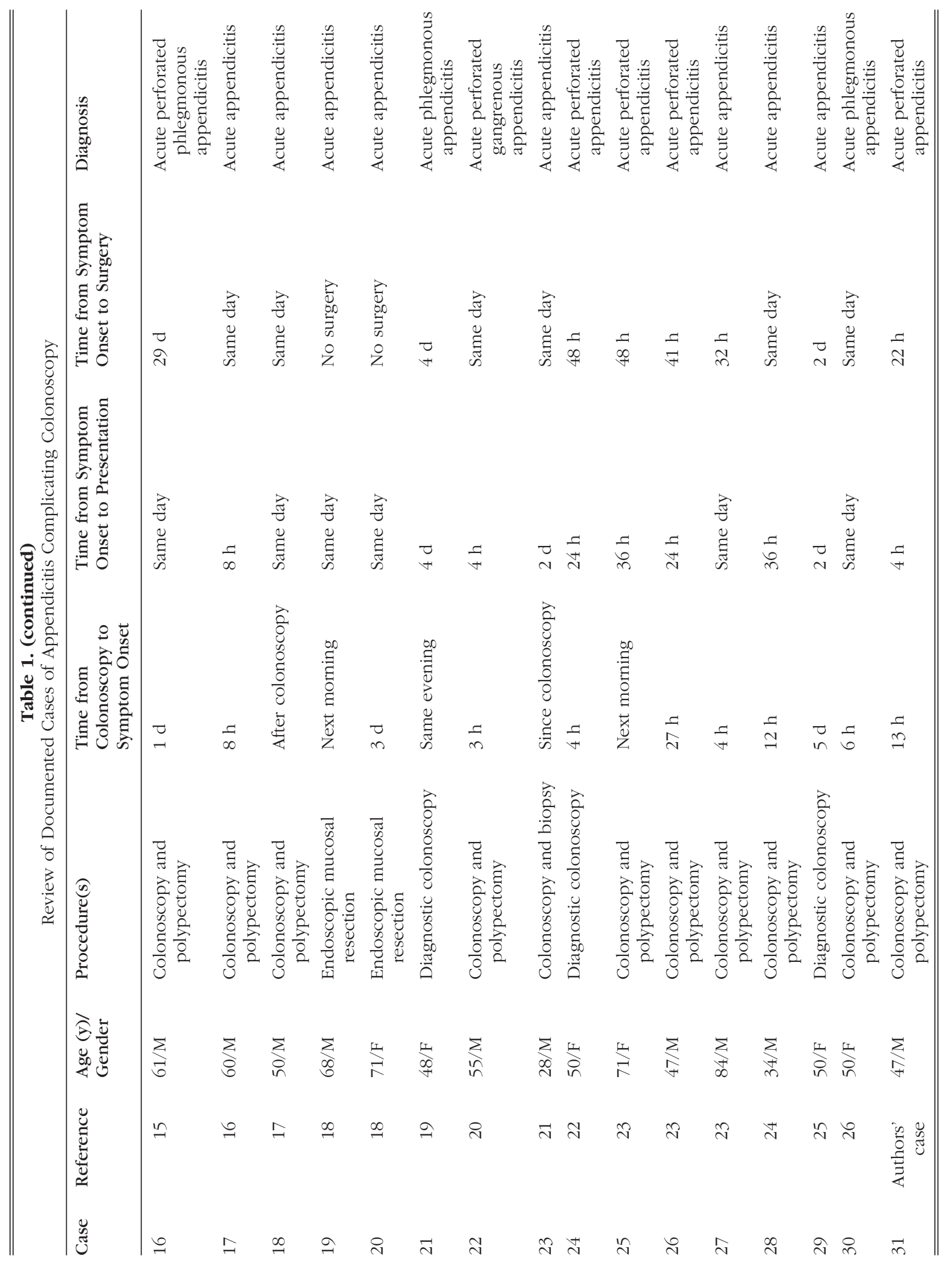


Table 2.

Time Intervals of Events in Postcolonoscopy Appendicitis

\begin{tabular}{|c|c|c|c|c|c|c|c|}
\hline Time $(\mathrm{h})$ & \multicolumn{2}{|l|}{$\leq 24$} & \multicolumn{2}{|l|}{$25-72$} & \multicolumn{2}{|l|}{$>72$} & Total \\
\hline Symptom onset to presentation & $21(67.7 \%)$ & $4(12.9 \%)$ & $5(16.1 \%)$ & - & $1(3.2 \%)$ & - & 31 \\
\hline Symptom onset to surgery & $11(40.7 \%)$ & $3(11.1 \%)$ & $8(29.6 \%)$ & - & $2(7.4 \%)$ & $3^{*}(11.1 \%)$ & 27 \\
\hline
\end{tabular}

*One interval appendectomy.

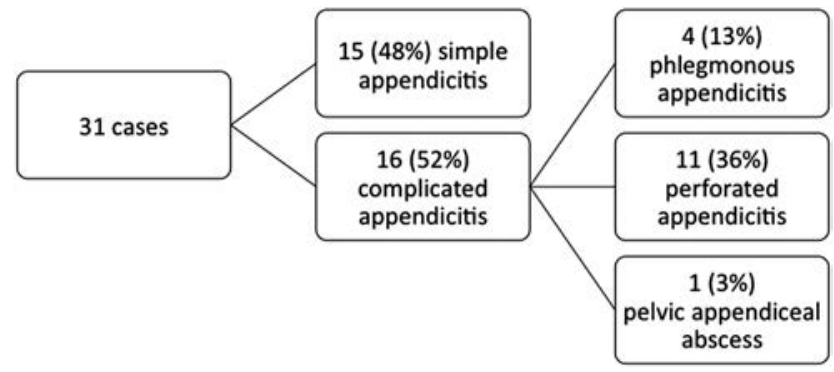

Figure 3. Summary of postcolonoscopy appendicitis diagnoses.

pelvic appendiceal abscess, and both deaths in the documented cases were among the 11 cases we reviewed.

Cases were classified into 4 treatment groups, with outcomes as demonstrated in Figure 4. Four patients were presumed to have an acutely inflamed appendix without perforation on the basis of clinical examination and CT imaging and were treated conservatively with antibiotic therapy alone. This group of patients improved over 3 to 6 days, and no complications or deaths were documented in this group of patients.

Nine patients were initially treated conservatively with antibiotic therapy or watchful waiting. However, these patients proceeded to appendectomy because of clinical progression. A review of these case reports shows that colonic perforation, postpolypectomy syndrome, or both of these conditions were considered as initial diagnoses in 6 of 9 cases. These patients were presumably treated conservatively initially because of the absence of pneumoperitoneum found on radiographs and failure to consider acute appendicitis in the differential diagnosis. Despite CT findings demonstrating acute appendicitis and clinical findings of acute appendicitis, one patient in this group was initially treated conservatively.

Two deaths that were identified in our review belonged to this second management category. The first death occurred ten weeks after appendectomy and was attributed to sepsis in the setting of advanced cardiac and renal disease. ${ }^{4}$ The second mortality occured 29 days post colonoscopy and was attributed to multiorgan failure after delayed diagnosis and surgery for a pelvic appendiceal abscess. ${ }^{12}$

The 17 patients who were treated with early appendectomy had uneventful recoveries and shorter hospital stays compared with patients who were initially treated conservatively. CT imaging was performed in 14 of 18 patients, and all findings showed changes consistent with appendicitis.

One patient had an unremarkable recovery after initial treatment with antibiotic therapy before undergoing a planned interval appendectomy.

\section{DISCUSSION}

Since the first case of acute appendicitis after colonoscopy was described by Houghton and Aston in 1988, only 24 similar articles have been published. As suggested by Houghton and Aston in their landmark article, the true incidence of this problem may be more common than the literature would suggest because of under-recognition, response to nonsurgical treatment, or spontaneous resolution. ${ }^{3}$ However, despite the increase in colonoscopy use in the past decade, its reported incidence has not risen. This suggests that postcolonoscopy appendicitis may well be an incidental pathology resulting from subclinical disease and not a true complication of colonoscopy.

Should there be a true relationship between colonoscopy and acute appendicitis, the advancement in our understanding of the etiology and pathogenesis has been limited and is largely theoretical. Several hypotheses have been proposed to explain the pathophysiologic mechanisms of acute appendicitis after colonoscopy. Aside from incidental appendicitis or pre-existing subclinical disease, these include barotrauma, propagation of a fecalith into 


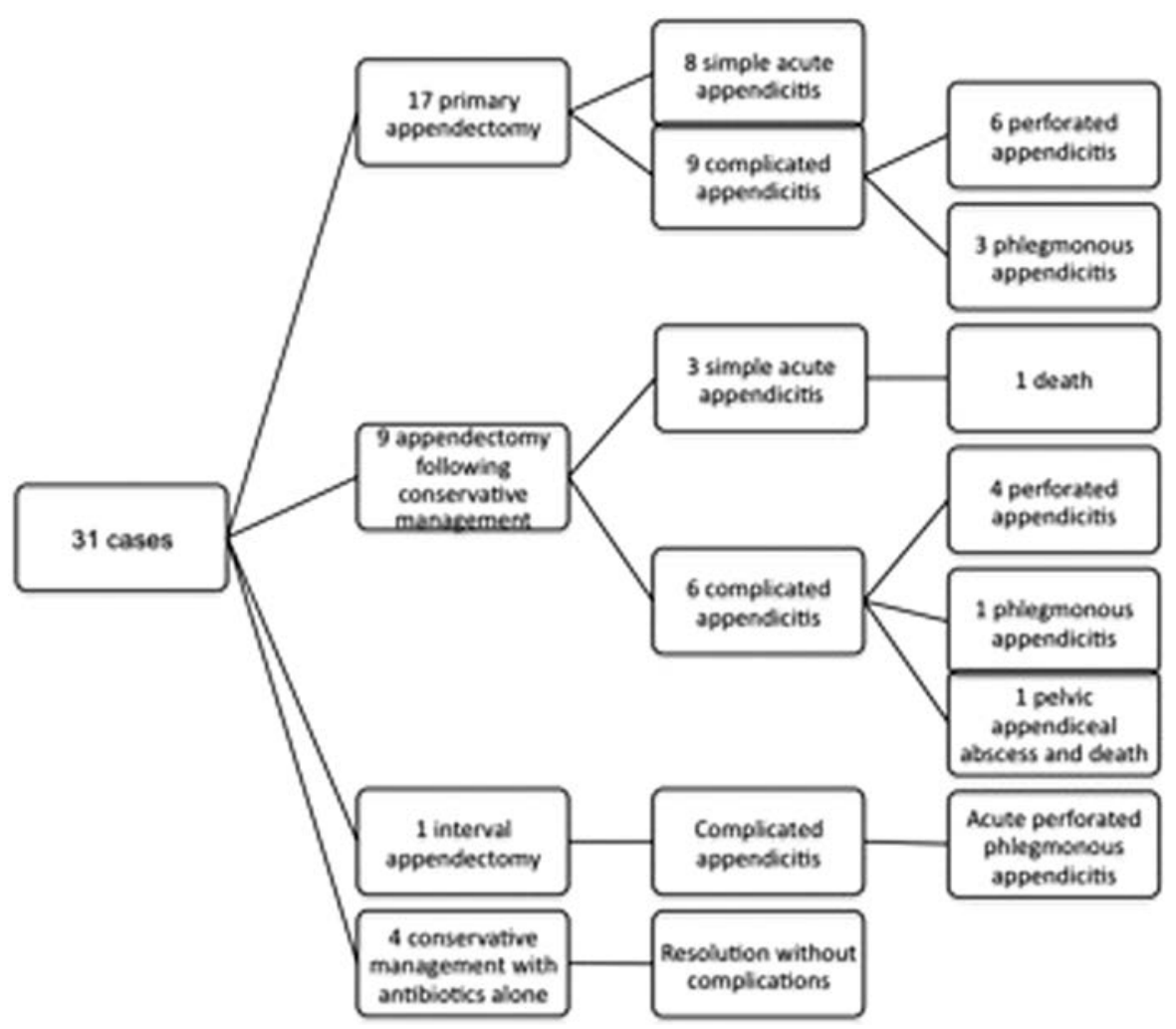

Figure 4. Treatment groups and outcomes in postcolonoscopy appendicitis.

the appendiceal lumen because of gas insufflation, and edema as a result of intubation of the appendiceal lumen. 6,7,10 These mechanisms may result in obstruction of the appendiceal lumen and subsequent progression to inflammation, gangrene, and perforation. Because all of these mechanisms are hypothetical or anecdotal, the absence of knowledge may contribute to under-recognition of acute appendicitis after colonoscopy.

Although acute appendicitis is a common and wellrecognized reason for patients to present with acute abdominal pain, reports of acute appendicitis after colonoscopy share a common theme of delayed diagnosis and delayed surgical intervention. ${ }^{26}$ The problem presented by acute appendicitis after colonoscopy may be the existence of shared symptomatology and examination findings with common colonoscopic complications such as colonic perforation and postpolypectomy syndrome. Hence, judicious use of radiologic investigations can improve diagnostic accuracy. The lack of awareness of acute appendicitis as a potential pathology in patients presenting with an acute abdomen after colonoscopy may also be contributory.

Seventy four percent of patients with acute appendicitis after colonoscopy developed symptoms of abdominal pain within 24 hours after their procedure. The close association between colonoscopy and the onset of symptoms suggests a relationship between the procedure and pathology. However, the diagnosis of postcolonoscopy appendicitis has been largely based on clinician opinion because of the lack of an established definition. The terms postcolonoscopy appendicitis and acute appendicitis complicating colonoscopy have been used interchangeably to describe acute appendicitis diagnosed at indefinite time intervals after colonoscopy. Acute appendicitis complicating colonoscopy implies a causal relationship between colonoscopy and acute appendicitis. Hence, the term acute appendicitis following colonoscopy or postcolonoscopy appendicitis is used preferentially because it avoids this connotation.

The conventional model of the natural history of appendicitis proposes that progression from simple to complicated appendicitis is a time-related process, with an increasing incidence of perforation correlating with an increase in the duration of symptoms. ${ }^{29}$ In Andersson's review article, he proposes an alternative explanation that challenges this observation: He suggests that the apparent increase in the proportion of perforated appendicitis with 
time is caused by selection because many cases of acute appendicitis undergo spontaneous resolution. ${ }^{28}$

The natural history of postcolonoscopy appendicitis is variable but appears to follow a more acute course, with a higher rate of progression to advanced pathology, when compared with conventional acute appendicitis. Sixteen of 31 (52\%) patients were diagnosed with complicated appendicitis compared with $16 \%$ to $28 \%$ in studies by Temple et al and Moss et al. ${ }^{27,29}$ However, this apparent higher rate of complications may be a result of selection bias because patients with postcolonoscopy appendicitis treated conservatively on a presumptive diagnosis of postpolypectomy syndrome may respond well to conservative treatment. Consequently, uncomplicated postcolonoscopy appendicitis may be underreported, leading to a higher rate of complications associated with appendicitis after colonoscopy compared with conventional appendicitis.

Although preadmission delay accounted for a delay in surgery for conventional appendicitis, postadmission delay led to increased time to surgical intervention in patients with postcolonoscopy appendicitis. ${ }^{27,29} \mathrm{~Pa}-$ tients with abdominal pain after colonoscopy were less likely to delay seeking medical attention compared with patients with conventional acute appendicitis, presumably because these patients were made aware of the symptoms of potential complications of the procedure. Delayed surgery in postcolonoscopy appendicitis can be explained by low clinical suspicion with or without failed conservative treatment. A semiquantitative comparison of 11 documented cases of conventional appendicitis shows that half of the total cases of perforation were clinician-dependent events. Although perforation may occur regardless of time factors, it does not negate the role of early diagnosis and surgery in limiting the sequelae of appendiceal perforation rather than preventing perforation. ${ }^{28}$

Progression of appendicitis despite initial conservative treatment with antibiotics resulted in delayed surgical intervention and was associated with increased morbidity and mortality. Frequent serial clinical examinations are recommended to detect advancing peritonism and hasten surgical intervention. Prompt appendectomy has long been the definitive treatment and standard of care for acute appendicitis because of the risk of progression to advanced pathology. This study demonstrates that the severity of pathology and complication rate in adult patients with acute appendicitis may be time dependent and therefore suggests that delaying appendectomy is unsafe. An acute surgery model in patients with acute appendicitis demonstrates that reducing the delay from the time of diagnosis to the operating room translates to a $47 \%$ risk reduction in perforation, a $56 \%$ risk reduction in complications, and a hospital stay of one fewer day. ${ }^{30}$

Polypectomy was performed in nearly $70 \%$ (21 of 31) of the cases reviewed, but no pathophysiologic relationship between polypectomy and postcolonoscopy appendicitis was suggested. A history of polypectomy may have resulted in a delayed diagnosis and initial nonoperative management because of a presumptive diagnosis of postpolypectomy syndrome in the absence of pneumoperitoneum.

Propagation of a fecalith into the appendiceal lumen during gas insufflation, although seemingly plausible, remains anecdotal because the presence of a fecalith has not been uniformly found in cases of acute appendicitis after colonoscopy. The presence of a fecalith was identified in 8 cases by means of radiologic imaging, gross surgical specimen analysis, or histology. The absence of a fecalith, however, was reported in 8 cases based on histologic findings, which suggest that an alternative mechanism of luminal obstruction may be contributory.

The natural history of acute appendicitis is variable and thus difficult to compare with postcolonoscopy appendicitis. Furthermore, the lack of an objective definition of postcolonoscopy appendicitis means that the diagnosis is based on clinician opinion. Accuracy of our retrospective study of the natural history of postcolonoscopy appendicitis is limited by the lack of quantitative data regarding its time frames and management. The reliability and precision of estimates must be interpreted with caution because of the small sample size.

\section{CONCLUSION}

Acute appendicitis after colonoscopy may be incidental or may be a true complication of colonoscopy. At present, the data available are inadequate to provide firm details on the natural history of acute appendicitis after colonoscopy. Regardless of whether postcolonoscopy appendicitis represents an incidental finding or a true complication of colonoscopy, consideration of acute appendicitis as a differential diagnosis of the acute abdomen after colonoscopy is important. It may minimize delayed diagnosis and thus reduce possible morbidity and mortality. It may also guide the decision of whether a conservative or surgical treatment algorithm is followed. There should be a multidisciplinary awareness of acute appendicitis as a potential 
complication of colonoscopy to facilitate effective management.

\section{References:}

1. Viiala CH, Zimmerman M, Cullen DJ, Hoffman NE. Complication rates of colonoscopy in an Australian teaching hospital environment. Intern Med J. 2003;33(8):355-359.

2. Hunt RH. Towards safer colonoscopy. Gut. 1983;24(5):371-375.

3. Houghton A. Aston N. Appendicitis complicating colonoscopy. Gastrointest Endosc. 1988;34(6):489.

4. Brandt E, Naess A. Acute appendicitis following endoscopic polypectomy. Endoscopy. 1989;21(1):44.

5. Segawa K, Suzuki T, Arisawa T, et al. A case of acute appendicitis developing after colonoscopy. Gastroenterol Endosc. 1992;34:1933-1937 [in Japanese with English abstract].

6. Vender R, Larson J, Garcia J, Topazian M, Ephraim P. Appendicitis as a complication of colonoscopy. Gastrointest Endosc. 1995;41(5):514-516.

7. Hirata K, Noguchi J, Yoshikawa I, et al. Acute appendicitis immediately after colonoscopy. Am J Gastroenterol. 1996;91(10): 2239-2240.

8. de Leusse A, Cuillerier E, MArteau P, et al. Acute appendicitis after colonoscopy. Gastroenterol Clin Biol. 1999;23(1):150-151. [in French].

9. Lipton S, Estrin J. Postcolonoscopy appendicitis: a case report. J Clin Gastroenterol. 1999;28(3):255-256.

10. Takagi Y, Abe T. Appendicitis following endoscopic polypectomy. Endoscopy. 2000;32(8):S49.

11. Kapral C, Wewalka F, Kopf C, Aufreiter M, Lenz K. Acute appendicitis after colonoscopy: causality or coincidence? Z Gastroenterol. 2003;41(10):999-1000. [in German].

12. Srivastava V, Pink J, Swarnkar K, Feroz A, Stephenson BM. Colonoscopically induced appendicitis. Colorectal Dis. 2004; 6(2):124-125.

13. Rosen MJ. Sands BE. Acute appendicitis following colonoscopy. J Clin Gastroenterol. 2005;39(1):78.

14. Petro M, Minocha A. Asymptomatic early acute appendicitis initiated and diagnosed during colonoscopy: a case report. World J Gastroenterol. 2005;11(24):5398-5400.

15. Izzedine H, Thauvin H, Maisel A, Bourry E, Deschamps A. Post-colonoscopy appendicitis: case report and review of the literature. Am J Gastroenterol. 2005;100(12):2815-2817.
16. Volchok J, Cohn M. Rare complications following colonoscopy: case reports of splenic rupture and appendicitis. JSLS. 2006;10(1):114-116.

17. Pellish R, Ryder B, Habr F. An unusual complication: postcolonoscopy appendicitis. Endoscopy. 2007;39 Suppl 1:E138.

18. Horimatsu T, Fu KI, Sano Y, et al. Acute appendicitis as a rare complication after endoscopic mucosal resection. Dig Dis Sci. 2007;52(7):1741-1744.

19. Chae HS, Jeon SY, Nam WS, et al. Acute appendicitis caused by colonoscopy. Korean J Intern Med. 2007;22(4):308-311.

20. Johnston P. Maa J. Perforated appendicitis after colonoscopy. JSLS. 2008;12(3):335-337.

21. Bachir NM, Feagins LA. Postcolonoscopy appendicitis in a patient with active ulcerative colitis. World J Gastrointest Endosc. 2010;2(6):232-234.

22. Appendicitis as a complication of colonoscopy. Sheikh AA, Watt J, Tee M, Selvasekar CR. *** JSCR. 2010;9:1.

23. Moorman ML, Miller JP, Khanduja KS, Price PD. Postcolonoscopy appendicitis. Am Surg. 2010;76(8):892-895.

24. Acute appendicitis after colonoscopy. Aguilar-Shea AL, Galardo Mayo C, Aranda Hernández J. ***. Med Clin (Barc). 2011 May 16. [Epub ahead of print] [ inSpanish].

25. Penkov P. Acute appendicitis following colonoscopy: causality or coincidence? ANZ J Surg. 2011;81(6):491-492.

26. Rodríguez-Otero Luppi C, Salas Muñoz J, Targarona EM, Rodríguez Blanco M, Bollo J, Trias M. Acute appendicitis after colonoscopy: coincidence or cause? Gastroenterol Hepatol. 2011 Jun 22. [Epub ahead of print] [ inSpanish].

27. Moss JG, Barrie KL, Gunn AA. Delay in surgery for acute appendicitis. J R Coll Surg Edinb. 1985;30(5):290-293.

28. Andersson RE. The natural history and traditional management of appendicitis revisited: spontaneous resolution and predominance of prehospital perforations imply that a correct diagnosis is more important than an early diagnosis. World J Surg. 2007;31(1):86-92.

29. Temple CL, Huchcroft SA, Temple WJ. The natural history of appendicitis in adults. A prospective study. Ann Surg. 1995; 221(3):278-281.

30. Earley AS, Pryor JP, Kim PK, et al. An acute care surgery model improves outcomes in patients with appendicitis. Ann Surg. 2006;224(4):498-504. 